\section{A (in)salubridade do} cárcere e outras causa mortis na Casa de Correção de Porto Alegre, 1855-1888

\section{The (in)salubrity of prison life and other causes of death in Porto Alegre Prison, 1855-1888}

\section{Tiago da Silva Cesar}

Professor, Departamento de História/Universidade Católica de Pernambuco.

Rua do Príncipe, 526

50050-900 - Recife - PE - Brasil

tiagocaesar@hotmail.com
CESAR, Tiago da Silva. A (in)salubridade do cárcere e outras causa mortis na Casa de Correção de Porto Alegre, 1855-1888. História, Ciências, Saúde - Manguinhos, Rio de Janeiro, v.22, n.3, jul.-set. 2015, p.829-848.

\section{Resumo}

$\mathrm{O}$ artigo analisa o fluxo das sensibilidades penais em relação aos cuidados médicosanitários dispensados aos presos da Casa de Correção de Porto Alegre entre 18551888. São observadas a interiorização e a instrumentalização de conceitos como "humanidade" e "civilização", sobretudo por parte daqueles indivíduos envolvidos diretamente ou com fortes chances de influenciar transformações concernentes às questões penais. Com efeito, além de gerar opinião pública favorável, as apreciações de governantes e notáveis levavam ao desenvolvimento de medidas e práticas concretas que aumentavam os mínimos vitais oferecidos à massa reclusa. Esse processo, entretanto, esteve longe de ser linear e harmônico como demonstram as doenças e a precariedade do cárcere.

Palavras-chave: prisões/história; doenças/ história; cuidados médicos/história; história do século XIX; Brasil.

\section{Abstract}

The article analyzes the flow of penal sensitivities in relation to medical and health care provided to prisoners in Porto Alegre Prison between 1855 and 1888. The internalization and the instrumentalization of concepts such as "humanity" and "civilization," especially by those individuals involved directly or with strong chances of influencing changes pertaining to penal issues, are observed. Indeed, in addition to generating favorable public opinion, the concerns of governing authorities and leading lights led to the development of concrete measures and practices that increased the minimum subsistence offered to the imprisoned class. This process, however, was far from linear and harmonic as witnessed by the diseases and the precariousness of prison life.

Keywords: prisons/history; disease/history; healthcare/history; history of the nineteenth century; Brazil. 
egundo Manoel Antonio Duarte de Azevedo (1873, p.29), então ministro e secretário de
Estado dos Negócios da Justiça:

A privação de liberdade, como meio de repressão empregado contra os que infringem a lei penal, impõe-nos a obrigação de prover a manutenção dos presos e o desenvolvimento de suas faculdades intelectuais e morais, pois que durante o tempo da detenção ficam inibidos de o fazer por si.

Pelo que nesse período da história penal-carcerária brasileira se entendia como responsabilidade do Estado em relação aos sentenciados, a fala do ministro é muito ilustrativa. Basicamente, a "manutenção dos presos" incluía a alimentação, o vestuário, a higiene pessoal, bem como o atendimento e os cuidados médicos oferecidos aos reclusos com moléstias e enfermidades graves.

Se quiséssemos acompanhar o processo de sensibilização penal no âmbito penitenciário, esses seriam os traços essenciais da vida em reclusão a ser observados com atenção. O "fluxo das sensibilidades penais" (Pratt, 2006, p.93), ${ }^{1}$ apesar de não ter sido algo linear, é bastante perceptível ante o cotejamento de atitudes e regulamentações por parte dos administradores do aparelho repressivo estatal ao longo do século XIX.

Não queremos dizer que tais mudanças se refletissem de forma absoluta e perene em todas as partes, erradicando os inúmeros elementos que tornavam a pena privativa de liberdade ainda menos suportável. Em todo caso, o que observamos é um processo que tendia à melhoria das condições de vida em reclusão, e não o contrário.

É interessante notar, nesse sentido, que - diferentemente das reformas surgidas na Espanha, com a intervenção das associações de caridade leigas de cunho ilustrado (Cesar, 2010, p.61-65), ou dos estudos e proposições estimulados por Howard na Inglaterra (McGowen, 1998), ou por meio de instituição filantrópica como na França (Duprat, 1980), ou, ainda, influenciado pelas experiências prisionais reformadoras como nos EUA (Rothman, 1998), ou da curta participação dos "homens bons" na promoção de certas melhorias e no alçamento de denúncias sobre as mazelas carcerárias em Portugal (Santos, 1999, p.45) -, no Brasil, igualmente ao que se deu na metrópole, os primeiros olhares sistemáticos para as abomináveis prisões só vieram com as comumente chamadas comissões de visitas às cadeias, de cunho estatal.

No Brasil independente, entretanto, contrastando com o que sucedeu em outros países latino-americanos durante as guerras de independência e no período imediato posterior, as péssimas condições carcerárias e os obscuros procedimentos penais não foram tomados como arma política, associando-os aos "horrores do colonialismo". Assim, enquanto alguns dirigentes políticos - como o próprio general José de San Martín - viram nas lúgubres imagens carcerárias o reflexo da tirania ou desídia do antigo governo (Aguirre, 2009, p.38-39), no Brasil, as primeiras ações reformistas já sob a égide de dom Pedro I serão apresentadas como um gesto "filantrópico" por parte de sua "majestade imperial". A ação benfazeja é anunciada como continuação de suas "virtudes inatas, herdadas de seus augustos progenitores" (França, 1826, p.14-15).

Simbolicamente, a aplicação do inciso XXI do artigo 179 da Constituição de 1824 não representou, em nosso caso, um corte radical com a política penal-carcerária do antigo regime, uma vez que as melhorias deviam ser entendidas como uma ação "natural" 
(de continuidade), tal como a ascensão do jovem monarca ao trono. O dito inciso rezava que as prisões seriam seguras, limpas, bem arejadas, observando a classificação dos réus conforme as circunstâncias e a natureza dos seus crimes. No entanto, a filantropia do imperador tinha seus próprios limites; por falta de cadeias "no resto da província e do Império" (Feijó, 1832, p.11), acabava circunscrita à Corte. ${ }^{2}$

Excetuando o que havia de exagero nesta última asseveração, e pelo que diz respeito ao caso sulino, há evidências muito antigas de comissões que se escandalizavam ante cenas de sofrimento alheio, como a descrita em 1831 pela então encarregada de visitar as prisões e os estabelecimentos de caridade, conforme estipulava o artigo 56 da lei de $1^{\circ}$ de outubro de 1828 (Moreira, 2009, p.119). A sua pertinência excusará a extensa citação:

Desculpai, senhores, o fogo com que a comissão falou em semelhante objeto, mas os gemidos dos infelizes troam ainda em seus ouvidos, a humanidade grita, a religião estremece, a civilização se eclipsa, e nossos corações não podem em segredo sofrer os violentos combates da razão e das sensações. É preciso, senhores, coibir tão detestáveis abusos. O castigo é necessário para a correção do crime, mas um castigo moderado, um castigo humano. Deixemos a barbaridade dos castigos para esses tempos tenebrosos, em que os homens não conheciam seus direitos e os dos outros homens. A barbaridade dos castigos traz funestas consequências. Os criminosos e os não criminosos que se acham presos, habituados a ouvir gemidos, se ensurdecem às aflições da humanidade e uns, sendo soltos depois de cumprida a sentença, e outros, quando a prepotência o quiser soltar, estarão habilitados para cometer toda a sorte de delitos, porque os gemidos da humanidade já não têm entrada em seu coração. É preciso, pois, remediar esses males, e a comissão assim o espera (p.120).

A importância do exposto pela comissão não residia apenas no seu conteúdo: mais do que se dizia, sua relevância estava no modo (linguagem) de relatar as misérias do cárcere. Observe-se, por exemplo, que o conceito de "civilização" possui aqui como seu antagonista o de "barbaridade". A ideia de "evolução" é o que separa e distingue as duas "eras". Assim, práticas penais que se assemelhassem às do antigo regime passavam automaticamente a ser vistas e até denunciadas por seu caráter anacrônico.

Conforme Foucault (2012, p.13), com a redefinição da "economia do castigo", o castigo comedido, ou seja, sem excessos e abusos que excedessem às leis, irrompe como o novo paradigma do "processo disciplinar", servindo, por conseguinte, de baliza, além da qual não convinha ultrapassar sem prejuízo para a sociedade que se queria implantar. A mentalidade que inaugurou a "era da sobriedade punitiva" (p.29) não só buscou dissimular o corpo supliciado como também procurou "sanear o sofrimento" (Pratt, 2006), já que não mais interessava apenas a subjugação do corpo, mas sim a repressão da alma:

A repressão da alma pareceu ao homem 'civilizado' o caminho ideal para exercer 'influências', em virtude de que seus efeitos eram mais permanentes que os proporcionados pelo castigo físico, além de ser um método que evitava o horror causado ante o espetáculo do sofrimento corporal, um tabu moderno (Barrán, 1991, p.82; destaques no original). ${ }^{3}$

Nesse sentido, e tendo em conta que são grupos da elite que normalmente estabelecem os padrões socioculturais, devemos tomar os relatos - tal como o anterior - como ações que 
auxiliavam a forjar/consolidar uma opinião pública favorável à sensibilização social acerca do sofrimento alheio. Claro está que, com o passar dos anos, a defesa da reforma penitenciária, com toda a carga humanitária nela embutida, também acabou se tornando um elemento notável dos discursos políticos que se propunham a modernizar o Estado. Quer dizer, simplesmente enunciar ou colocar essa reforma na agenda política significava, para políticos individuais ou partidos, apresentar-se como aliado potencial do "anjo" do progresso. ${ }^{4}$ Em todo caso, tê-los em consideração pela análise histórica ajuda a entender melhor a mescla da massa que serviu na cimentação desse processo cujos efeitos práticos se refletiam no tratamento e na vida encarcerada. Prova disso podem ser as construções carcerárias de nova planta, os regulamentos e outras modificações introduzidas depois de veementes queixas ou denúncias externas.

Somos conscientes de que esses elementos não estão isentos de intenções de poder, visando a uma melhor administração ou a um controle mais eficiente, mas nem por isso deixam de ser provas de uma mudança comportamental em relação ao outro. Do contrário, como poderíamos entender certos gestos e concessões por parte das autoridades, algumas das quais fugiam completamente às normas disciplinares? Ainda que os presos tivessem, de modo geral, acesso à alimentação, como diria Perrot (2006, p.260), baseada na concepção de um "mínimo vital", não era sem a interiorização e a consecutiva instrumentalização de certos conceitos como o de "humanidade" que esse reconhecido mínimo vital seguia avançando, às vezes entre vaivéns.

\section{Práticas profiláticas e cuidados médicos}

Aproximadamente dois anos depois de inaugurada a primeira seção da Casa de Correção de Porto Alegre, foi promulgado, no dia 27 de fevereiro de 1857, seu primeiro regulamento interno (Regulamento..., 2001). É precisamente nesse conjunto de normas que também encontraremos pela primeira vez especificadas, formalmente, quais práticas deveriam ser observadas para se garantir no recinto carcerário um estado salutar.

Dos seus 51 artigos, cabe aqui destacar apenas o conteúdo de quatro deles (38, 39, 40 e 41), além do parágrafo 13 do artigo 35. São esses que tratam pontualmente dos procedimentos a ser acionados em caso de doenças infectocontagiosas e dos cuidados que se dispensariam aos pacientes. O referido parágrafo 13 do artigo 35, por exemplo, estipulava que os presos padecentes de moléstias contagiosas ou repugnantes fossem conservados numa cela específica, a de número 25.

O preso que se apresentasse doente só era enviado ao hospital da Santa Casa de Misericórdia (HSCM) depois de examinado e de reconhecida a moléstia pelo facultativo da cadeia. Uma vez no hospital, segundo ainda o artigo 38, seria "conservado com toda a segurança e tratado com humanidade". Contudo, esse tratamento não deveria ultrapassar o tempo estrito de convalescença, tendo o preso, a partir de então, que regressar à prisão improrrogavelmente (art. 39). Aos enfermos de doenças crônicas aconselhados pelos médicos a dar passeios ao ar livre seria facultada tal autorização "uma ou outra vez dentro dos corredores da cadeia, com as portas fechadas, individualmente", sob vigilância cerrada (art. 40). 
Já o artigo 41 dispunha sobre as medidas de higiene pessoal. Estabelecia que os presos tomariam banho em tinas colocadas no pátio interior da cadeia, teriam sua barba raspada ao menos uma vez por semana e o cabelo cortado mensalmente. Ante a emergência de epidemias, é possível que essas práticas ainda se incrementassem, como o que documentou Moreira (2009, p.122), em face do medo do cólera de 1886, quando o médico da cadeia ordenou que os presos passassem a tomar banho duas vezes por semana e que os tubos com as fezes fossem desinfectados.

Continuando com as disposições, no artigo 41, todavia, ordenava-se que, na falta de presos que desempenhassem o serviço, poderia ser contratado um barbeiro para atender aos sábados ou nos dias previamente indicados pela autoridade encarregada da inspeção.

Ainda que bastante simples em comparação com o promulgado em 1896, esse regulamento continha todos os preceitos básicos de limpeza e asseio para se evitarem as doenças, além de servir de manual de instruções para casos infectocontagiosos. Quanto aos procedimentos de limpeza, segundo o artigo $6^{\circ}$ : "As prisões serão varridas todos os dias, pela manhã, e lavadas de 15 em 15 dias, conservando-se sempre em estado de limpeza" (Regulamento..., 2001).

É difícil medir até que ponto essa e outras normas eram observadas ao pé da letra, mas há indícios, por exemplo, da lavagem das celas, que atestam sua regularidade ao longo dos anos. Em representação de seus companheiros de infortúnio, o preso Germano Wagner, em 19 de dezembro de 1885, redigiu e enviou uma carta ao presidente da província na qual requeriu o derrogamento do decreto que proibia a prática de fazer fogo e lavar as roupas dentro dos cárceres.

Conforme visto, a negativa da disposição ocorria para preservar o assoalho, que vinha, supostamente por esses motivos, sofrendo um rápido desgaste. Defendendo suas prerrogativas, o requerente fez constar, primeiramente, que as causas reais que danificavam o assoalho não eram outras senão a umidade decorrente das lavagens semanais, os ratos e a ação cortante da areia grossa ao longo de 32 anos:

Exmo. senhor; o estrago do assoalho desta cadeia tem sido admiravelmente lento, à vista de três fatores que durante 32 anos trabalham incessantemente a destruí-lo, e que são: a umidade pelas lavagens semanais, os ratos e a ação cortante da areia grossa, movida pelos pés calçados - o assoalho dos xadrezes do pavimento inferior está muito estragado, enquanto no pavimento superior há muitos xadrezes com o assoalho em perfeito estado reclamando os outros pequenos reparos, porém em xadrez algum há o menor vestígio de o assoalho ter sofrido pelo fogo (Requerimento..., 2001).

E, em segundo lugar, que a licença do uso do fogareiro remontava a 1876, graça concedida pelo chefe de Polícia Ledo Vega, sem que tal fato durante todo esse tempo tivesse produzido estrago algum no assoalho das celas.

Pelo exposto até aqui, fica evidente que certas práticas higiênicas preventivas (lavagens, varreduras, caiações) eram cumpridas assiduamente. De igual maneira, podemos asseverar sobre o cuidado dispensado aos presos padecentes de moléstias graves ou crônicas, por meio dos livros de entrada da Santa Casa de Misericórdia e da construção e dos melhoramentos das enfermarias, como veremos.

À falta de uma enfermaria própria, até $1^{\circ}$ de outubro de 1861, todos os reclusos enfermos de gravidade eram (mediante prévio exame) enviados ao HSCM. ${ }^{5}$ Em meados da década de 
1850, o estabelecimento possuía cinco enfermarias, sendo a primeira dos "homens", na qual se atendiam também os praças do corpo policial; a segunda, das mulheres; a terceira, dos menores do Arsenal de Guerra; a quarta, dos membros da Sociedade Portuguesa; e a quinta e última, a dos presos civis pobres. Sobre esta, a provedoria da Santa Casa informou ainda, em relatório referente ao ano de 1855, que, com o dinheiro provincial, foram feitas as obras necessárias tendo em vista o "arranjo e segurança de uma nova enfermaria" para os presos civis (Fagundes, 1856, p.4, 9-10).

Não temos muitas informações sobre essa enfermaria, mas o pouco que sabemos já havia causado calafrios em comissões contemporâneas que a visitaram em meados do século XIX. Durante a epidemia de cólera de 1855, fora descrita em documento de 10 de novembro, com as seguintes palavras:

Neste momento acaba de receber a Comissão a Portaria de V. Ex. em que ordena que indo à enfermaria, onde são tratados os presos civis na Santa Casa, examinou e achou que, estando colocada em um subterrâneo onde a umidade é constante, o ar pouco renovado, o assoalho todo arruinado, e em parte não existe, e muito imunda, não devem ser conservados ali os enfermos... (Witter, 2007, p.77-78).

A "imagem" dessa enfermaria nos remete às descrições dos velhos aljubes tão característicos do período colonial. Claro está que sua localização num lugar de ar pouco renovável certamente se dava por questões de segurança.

Não obstante, foi curiosamente devido às "contínuas fugas, que ali aconteciam", ${ }^{6}$ que se optou por transferir a enfermaria para o interior da Casa de Correção (Leão, 1861, p.15-16). Inaugurada em outubro de 1861, pareceu preencher as necessidades por mais de 20 anos, até que sua sala passou a ser considerada "pouco espaçosa" (Lima, 1883, p.42).

A enfermaria de presos ocupava a cela nove, e não contava com latrina nem quarto para o enfermeiro, como constava na proposta de reforma e ampliação. Avançando sobre as celas dez e 11, além desses novos espaços, havia uma enfermaria que comportaria mais de vinte "doentes" (Lima, 1883, p.62). Entretanto, era visível sua falta de isolamento em relação aos demais compartimentos do estabelecimento; pela disposição dos planos, apenas as paredes a separavam das celas contínuas.

É importante ressaltar que, excetuando os gastos feitos com a reforma propriamente dita, que corria por conta dos cofres provinciais, os utensílios, os medicamentos e as dietas ficavam a cargo da Santa Casa de Misericórdia. Sabe-se que o governo provincial destinava uma parte do orçamento para cobrir as atenções prestadas aos menores do Arsenal, praças da polícia e presos pobres, mas, segundo os relatórios da provedoria do hospital, esses valores não chegavam para pagar os gastos que o atendimento alcançava, pela alta dos gêneros alimentícios e remédios, ou simplesmente pelo aumento do número de atendidos.

Com claro tom queixoso, encontramos o provedor, o marechal de campo Luiz Manoel de Lima e Silva (1872, p.7):

Na enfermaria da cadeia a cargo da filantropia deste pio estabelecimento, sem ajuda alguma dos cofres públicos, foram tratados durante o ano 21 presos pobres e dez particulares, aos quais se destribuirão medicamentos no valor de $1.083 \$ 200$, bem como as dietas necessárias, e todo o preciso para o serviço das camas, como seja, colchões, travesseiros, fronhas, lençóis, escarradeiras e urinóis. 
Apesar desses testemunhos, não podemos asseverar sobre a qualidade das atenções médicas destinadas aos presos pobres. De acordo com os relatórios da provedoria do HSCM, as reclamações em relação aos medicamentos e às dietas fornecidos aos presos enfermos se arrastavam desde longa data, conforme documenta a continuação:

A Santa Casa, como v. ex $x^{a}$ sabe, está situada em um extremo da cidade, e a cadeia civil, no outro.

O receituário que dali vem diariamente para aprontar-se na botica da Santa Casa volta com não pequena demora; a aplicação dos medicamentos é sempre tardia, e o mesmo acontece com o serviço das dietas, devido à grande distância.

O serviço é sempre malfeito, a fiscalização na enfermaria é sempre frouxa, a despesa que faz a Santa Casa é muito maior do que a que faz com qualquer outra do estabelecimento, e com grave prejuízo dos pobres enfermos.

Aquela enfermaria penso que devia estar a cargo da administração da cadeia e sob as vistas da autoridade policial, e não a cargo da Santa Casa (Coelho Junior, 1873, p.7).

Dez anos depois, os problemas seguiam basicamente os mesmos. Na fala de José Antonio de Souza Lima reproduziu-se o parecer bastante negativo do médico responsável pelo serviço sanitário do estabelecimento penal, Manoel Martins dos Santos Penna, que o qualificou "sem regularidade nem conveniência". Em palavras do facultativo: "Do edifício da cadeia ao da Santa Casa, vai uma grande distância a vencer, e sendo os remédios e dietas conduzidos pelas correntes, acontece que chegam sempre frios e a má hora" (Lima, 1883, p.42).

Como solução para o problema, Penna indicava que o conveniente era deixar as dietas a cargo do mesmo fornecedor do correcional, mediante contrato especial, e os medicamentos sob a responsabilidade de uma farmácia mais próxima, obrigada a mandá-los ao estabelecimento quando solicitados. Todavia, sugeria que se colocasse à sua disposição uma ambulância para os casos urgentes (Lima, 1883, p.42). ${ }^{7}$ Em qualquer caso, nada indica que a transferência da enfermaria dos presos - da Santa Casa para o interior da Casa de Correção - tenha gerado melhora substancial para seus usuários, não pelo ao menos quanto aos serviços prestados.

Com efeito, a comissão de notáveis que vistoriou o estabelecimento penal em 1885 disse que a comida destinada aos enfermos, além de ser fornecida apenas uma vez ao dia pela Santa Casa, era a mesma para todos. Segundo a comitiva, "consistia ela em dois caldeirões abundantes de caldo, onde se viam grande quantidade de ossos com pouca carne, de [sic] envolta com arroz e alguns quartos de galinha" (Pesavento, 2009, p.40).

Por intermédio de relatórios mais antigos, sabemos, por exemplo, que entre setembro e outubro de 1868 havia na enfermaria 18 presos tratados diariamente "a galinha" (Silva, 1868 , p.11). E pouco mais resta dizer que aqueles que podiam pagar por melhor atendimento certamente recebiam tratamento e alimentação mais variados, ademais de condizentes com sua enfermidade. ${ }^{8}$

Dito isso, falta ainda ver quais eram, precisamente, as moléstias mais recorrentes entre a população carcerária, suas possíveis causas e algumas taxas de mortalidade. 


\section{As doenças do cárcere}

Antes de atribuirmos as doenças e dolências sofridas pelos presos da Casa de Correção somente às misérias do cárcere, devemos olhar, com maiores chances de acerto, primeiramente para os indivíduos que alimentavam o aparelho prisional na segunda metade do século XIX. Nessa direção, parece-nos de suma importância o que os dados sociológicos dos presos atendidos pelo HSCM nos revelam sobre suas condições socieconômicas.

Nos livros de "porta" do mencionado hospital, entre outros dados de interesse, dispomos de sexo, idade, estado civil, ocupação, naturalidade e, não sempre, da cor do preso enfermo baixado. Temos de informar que, dos 208 indivíduos registrados somando os anos de 1856, 1861 e 1862, apenas três eram mulheres. Do total de presos, 66\% tinham entre 21 e 40 anos de idade, estando insertos, portanto, em plena faixa de maior capacidade laboral dos indivíduos adultos. A maioria, 82\%, era de solteiros (171), e apenas 18\% deles eram casados (37). ${ }^{9}$

A essa caracterização de uma população carcerária com predominância masculina e relativamente jovem e solteira, devemos acrescentar suas naturalidades e ocupações. É realmente sintomático que pouco mais da metade do total de atendidos pela enfermaria dos presos civis, 54\%, nasceu fora do Rio Grande do Sul, em outras províncias ou no exterior. Observa-se, portanto, que, além de jovens e solteiros, a alta mobilidade também parecia ser um traço significativo dessa massa carcerária.

Em relação às ocupações dos presos baixados, a maioria foi registrada com a expressão "não tem", mas sabemos que esses homens se distribuíam entre as mais variadas profissões: pedreiros, alfaiates, comerciantes, ferradores, carpinteiros, marinheiros e marítimos, ourives, sapateiros, pintores, marceneiros, lavradores, campeiros, carreteiros, caixeiros etc. (Matrícula..., 1865). Em seu conjunto, são ocupações típicas de uma sociedade tradicional e pouco desenvolvida, na qual os indivíduos das camadas menos abastadas se viam, não raramente, na imperiosa necessidade de desempenhar mais que um ofício para sobreviver, enfrentando longas jornadas de trabalho.

Sobre o elemento "cor", não havia tal informação em todos os anos contidos nos livros de entrada, e em alguns ainda é fragmentária. Porém, tudo leva a crer que os atendidos compreendiam majoritariamente o grupo dos não brancos, ou seja, "pretos", "pardos" e "chinas". Para 1862, um dos anos de nossa amostra, do total de 38 atendidos, 15 eram de cor "branca", dez, "preta", sete, "parda", quatro, "china" e em dois não constava a característica étnica. Para a população carcerária de 1857, Silva (2005, p.47) verificou, por exemplo, que apenas $24 \%$ dos presos eram brancos, enquanto aproximadamente $76 \%$ não o eram, do total de 179 reclusos. No ano seguinte, os primeiros contabilizavam 45\%, e os não brancos outros 55\%. Conforme indicam as estatísticas, essa foi a tendência até o final do século XIX.

Esses dados introdutórios são suficientes e necessários para se ter uma ideia mais precisa sobre quem eram aqueles indivíduos que normalmente constituíam a "carne presidiária" da Casa de Correção de Porto Alegre em meados do século XIX. A partir deles, podemos supor que, dada a origem socioeconômica da maioria, muitas das doenças que figuram nos referidos livros de porta do HSCM não deviam ser desconhecidas da trajetória de vida daqueles populares. A própria insalubridade não era elemento exclusivo dos cárceres, hospitais, quartéis 
etc. Pelo contrário, é bastante sabido que grande parte das moradias de populares tampouco apresentava condições razoáveis de habitação.

Em muitos aspectos, a vida em liberdade não era muito mais salubre para as classes menos favorecidas, se levarmos em conta seus ofícios, suas moradias, os serviços sanitários da época, as vestimentas, o asseio pessoal, a alimentação etc. Detrás de uma determinada enfermidade, em muitos casos poderiam estar longos anos de alimentação deficitária ou o consumo contínuo de alimentos e água em condições pouco higiênicas etc. ${ }^{10}$

As misérias do cárcere, portanto, nem sempre eram as únicas causas dos problemas de saúde dos detentos, já que corpos fragilizados pelas precárias condições da vida pregressa, muitas vezes, só acabavam acentuando sua vulnerabilidade entre as grades.

Tabela 1: Doenças e dolências sofridas pelos presos em porcentagens, 1856-1862

\begin{tabular}{lrrrrrrrr}
\hline \multirow{2}{*}{ Enfermidades } & \multicolumn{2}{c}{1856} & \multicolumn{2}{c}{1861} & \multicolumn{2}{c}{1862} & \multicolumn{2}{c}{ Soma } \\
\cline { 2 - 9 } & Total & $\%$ & Total & $\%$ & Total & $\%$ & Total & $\%$ \\
\hline Venéreo-infectoparasíticas & 9 & 7 & 14 & 33 & 4 & 10 & 27 & 13 \\
Sistema digestivo & 41 & 32 & 9 & 21 & 11 & 29 & 61 & 29 \\
Sistema respiratório & 54 & 43 & 7 & 16 & 11 & 29 & 72 & 35 \\
Reumáticas & 3 & 2 & 1 & 2 & - & - & 4 & 2 \\
Contusões e feridas diversas & 7 & 5 & 3 & 7 & 9 & 24 & 19 & 9 \\
Tumores e úlceras diversas & - & - & 4 & 9 & 2 & 5 & 6 & 3 \\
Afecções de pele diversas & 2 & 2 & 2 & 5 & 1 & 3 & 5 & 2 \\
Outras & 11 & 9 & 3 & 7 & - & - & 14 & 7 \\
\hline Total & 127 & 100 & 43 & 100 & 38 & 100 & 208 & 100 \\
\hline
\end{tabular}

Fonte: Matrícula..., 1865.

Entre as afecções mais recorrentes que atingiram os 208 presos da amostra, figuraram disparadamente as do sistema respiratório, 35\%, seguidas das enfermidades do sistema digestivo, 29\%, e, em terceiro lugar, as de caráter venéreo-infectoparasíticas, $13 \%$ do total. ${ }^{11}$ Conforme podemos observar na Tabela 1, outras dolências também se repartiam entre os ingressados, mas suas incidências, como se verifica, não são nem de longe comparáveis com os males compreendidos nas três primeiras categorias.

Pneumonias, bronquites, asma e supressão de transpiração foram as protagonistas entre as doenças respiratórias. O fato de de estarem situados em frente ao Guaíba e banhados continuamente pelos ares gélidos do inverno, o escasso agasalho, juntamente com a aglomeração nos cárceres e uma alimentação débil certamente constituíam elementos fatais para contrair tais afecções, algumas delas tão mortais como a pneumonia e a tuberculose.

Apesar de não se encontrarem devidamente refletidos na respectiva tabela, os problemas respiratórios deviam ser, entre a população carcerária, mais comuns do que se podia perceber a olho nu. É importante salientar que resfriados, gripes e bronquites nem sempre levavam seus padecentes às enfermarias do estabelecimento.

O segundo grupo de moléstias sofridas pelos presos civis que mais figuraram nos registros do HSCM compreendia as do sistema digestivo: diarreia, prisões de ventre, indigestões, 
hepatite, gastrite, gastro-hepatite ou gastrenterite pareciam minar a saúde dos presos. Talvez sintomas de outras enfermidades destaquem-se pela incidência das duas primeiras; no entanto, desarranjos gastrintestinais tinham de ser igualmente recorrentes.

No balanço realizado para o período entre $1^{\circ}$ de julho de 1860 e 30 de junho de 1861, as moléstias que predominaram nas enfermarias sob a responsabilidade da Santa Casa de Misericórdia foram as afecções pulmonares e as do "tubo digestivo", e, segundo a avaliação médica, se devia "presumir como causas o uso da água do rio, pouco cuidado higiênico e nenhuma atenção à qualidade dos alimentos" (Leão, 1861, p.15). Para o período imediatamente anterior, $1^{\circ}$ de julho de 1859 até 30 de junho de 1860, as "inflamações do tubo intestinal, das vísceras próximas e do aparelho dos pulmões" tinham sido as dolências mais clinicadas nas enfermarias (Leão, 1860, p.22).

Vermes e parasitas podiam provocar diarreia; água de má qualidade e alimentos estragados, também. O que chama atenção, para 1856, é a inexistência de presos baixados por cólera, corroborando, em parte, a análise de Witter (2007, p.83) sobre o tempo de duração da epidemia de $1855 .{ }^{12}$

Assim como foi percebido no caso das doenças de caráter respiratório, não nos parece que os números de pacientes com moléstias do sistema digestivo representem a dimensão que deviam ter no cotidiano carcerário. Provavelmente, a maioria dos presos sofria de um ou mais problemas gastrintestinais em algum momento de suas vidas encarceradas.

As doenças venéreo-infectoparasíticas também faziam parte dos problemas graves encontrados entre a população reclusa. Cancro, úlceras sifilíticas ou sífilis eram mazelas presentes no ambiente carcerário. Além da disenteria, muito presente na população livre, também estavam as contagiosas, como a varíola e a parotidite, que não grassavam menos na capital da província. A sarna e as boubas também deviam ser recorrentes, apesar dos poucos casos registrados.

É curioso observar que não aparecem presos sendo atendidos por febres, mas podemos imaginar que tanto as doenças infectoparasíticas quanto as do sistema digestivo, respiratório e nervoso deviam causá-las em algum momento do padecimento. Febres altas podiam levar ao que se chamava de "congestão cerebral" ou ser o resultado de infecções graves.

Dentro desse quadro de enfermidades vividas entre grades, há que referir as dores reumáticas e de dentes, os problemas de pele, laringite, oftalmia, tumores etc., ademais de uma ampla variedade de feridas. Contusões na face ou feridas na garganta, no pescoço, na cabeça, nos dedos da mão, nos braços, nas costas ou, ainda, as provocadas por arma de fogo nos levam a pensar em possíveis agressões sofridas por esses indivíduos, algumas delas, talvez, no convívio com seus companheiros de infortúnio.

Tendo que conviver forçadamente com pessoas desconhecidas, não seria de estranhar que surgissem animosidades no dia a dia, gerando atritos que em ocasiões pudessem ter desfechos violentos, quando não fatais. Em relação aos maus-tratos ou castigos infringidos por "pessoas autorizadas", fica a dúvida sobre o que realmente significava, em termos médicos, a expressão "castigado", lavrada no registro do preso Mauricio (de Antonio Alves Azambuja), filho de Maria, nascido na província, então com 21 anos, solteiro. Mauricio permaneceu 12 dias na enfermaria do HSCM, do dia 14 até 26 de outubro de 1856 (Matrícula..., 1865), talvez restabelecendo-se da "correção" propriamente dita ou das moléstias causadas pelas feridas abertas. ${ }^{13}$ 
Igualmente desconcertante para o pesquisador são os casos de presos dando entrada no HSCM por "alienação mental". Não se sabe ao certo se eram pessoas que haviam perdido suas faculdades durante a privação de liberdade ou se eram alienados antes da chegada à prisão. Em qualquer caso, sabe-se que, historicamente, as cadeias e as santas casas foram os receptáculos mormente privilegiados na hora de retirá-los de circulação, tanto do seio de suas famílias como do cotidiano urbano. ${ }^{14}$

Outro elemento nem sempre tido em conta, mas em muitos casos essencial para entender certas doenças ou dolências crônicas, é o histórico carcerário dos indivíduos, já que muitos presos eram enviados à capital para cumprir suas sentenças depois de haver estado reclusos vários meses nas cadeias do interior da província.

É difícil crer que nesses estabelecimentos, nos quais os carcereiros se queixavam constantemente de baixos ordenados, os réus tivessem uma estância mais salutar que na Casa de Correção. Pelo contrário, sabemos por diversos presidentes da província que, devido à falta de segurança em muitas celas, a utilização de algemas, ferros e outros instrumentos para evitar evasões eram práticas muito comuns (Muritiba, 1856, p.38; Coelho, 1856, p.66; Leão, 1859).

Não se deve esquecer, tampouco, o impacto que os longos trajetos e as péssimas condições de viagem durante os traslados entre as instituições penais, ou daquelas às judiciárias, tinham sobre a saúde de indivíduos que, em geral, vestiam-se e se alimentavam de forma precária. Cabe insistir, por último, que "criminosos de importância", isto é, pronunciados especialmente por crimes de morte em diversos termos, eram recorrentemente enviados ao correcional de Porto Alegre, devido à falta de segurança das cadeias municipais.

\section{A estatística da enfermaria dos presos civis}

Durante a segunda metade do século XIX, a população reclusa da Casa de Correção estava composta, basicamente, pela "arraia-miúda" da sociedade rio-grandense. Ainda que os níveis de escolaridade não digam tudo, nem por isso devem ser desconsiderados da análise histórica. Tanto em 1856 como em 1861, Silva (2005, p.46) encontrou índices de analfabetismo entre os presos enviados para a Casa de Correção que ultrapassavam 50\% dos detentos.

Também a curiosa exposição feita por Faria Lemos, em 1878, sobre como aproveitar melhor as dependências do estabelecimento, expunha a origem socioeconômica dos grupos sociais que alimentavam o ultrapassado sistema prisional. Depois de apresentar os tipos de salas, quartos e celas da instituição, entre eles três quartos no pavimento superior para os presos "privilegiados", sugeriu o presidente que:

Sendo raros os presos que podem alegar imunidades, bem se poderiam aproveitar alguns dos compartimentos que lhes são destinados, e quase sempre se acham desocupados, para a prisão das mulheres, feitas as obras necessárias a seu isolamento e incomunicabilidade (Lemos, 1878, p.16).

A pobreza dos indivíduos, somada aos inconvenientes do encarceramento em condições insalubres, além de aumentar a miséria humana, causava doenças e dolências que não raramente levavam à morte. Os relatórios dos presidentes da província, assim como outras fontes oficiais, revelam (o que seus habitantes sabiam perfeitamente) uma precariedade endêmica. 
Em 1885, por exemplo, uma comissão integrada por Achylles Porto Alegre, Júlio de Castilhos, Felicíssimo de Azevedo, João Câncio Gomes e Ramiro Barcellos pintou o seguinte quadro:

Todos os compartimentos são ocupados pelo quádruplo de pessoas que podem neles habitar; assim é que, em um xadrez que tem dois metros e meio de largura sobre cinco de comprido, contamos catorze mulheres. Expliquemo-nos melhor. Nesse antro, que serve de recolhimento, contou a comissão catorze embrulhos de esteiras encostados às paredes, os quais, abertos à noite sobre o assoalho em ruínas, formam, com os andrajos que eles contêm, outras tantas camas. No centro dessas duas turmas de camas fica o espaço de metro e meio de largura, onde se acomodam as infelizes moradoras, com o tubo das matérias fecais e uma grande bacia, onde estavam lavando roupa; para completar este quadro, notou a comissão os sinais estampados nas negras paredes, da água que por elas corre, vinda do andar superior, que a recebe do telhado, que se acha em pouco melhor estado do que o assoalho da casa. Poderá se fazer ideia dessa inquisitorial prisão, considerando-se o desespero dessa miserável gente, amalgamada como objetos em uma caixa, recebendo sobre si durante a noite a água da chuva sem ter por onde se desviar. Tal é o estado da Cadeia Civil da capital da Província do Rio Grande (Pesavento, 2009, p.37).

Na fala do presidente Henrique Pereira de Lucena, de março de 1886, ainda podemos escutar os ecos desse relatório, fruto das averiguações da nominada comitiva de notáveis. Segundo Lucena (1887, p.161):

Realmente o estado de aglomeração dos presos, por falta de espaço, em cárceres pequenos, falta de condições higiênicas, que servem ao mesmo tempo de dormitórios, refeitorias, oficinas, depósito de materiais de trabalho, latrinas etc., favorecendo na maior escala o desenvolvimento da infecção física e moral, é causa mais que poderosa para levar ao último grão de depravação esses infelizes, com grave atentado contra as leis sociais e humanas.

Superlotação, celas em ruína e sujeira constituíam a tríade das queixas e denúncias que vinham sendo realizadas havia muito tempo (Lemos, 1878, p.15). E se a isso somamos a má alimentação e o consumo de água em condições duvidosas, o pouco asseio, a falta de vestuário adequado para as diferentes estações, a escassa atividade ao ar livre e os vários problemas de relacionamento que causavam reações violentas e elevados níveis de estresse, podemos asseverar que o terreno era suficientemente propício para as enfermidades que, ao contrário do que se pensava e dizia, entravam mais no cárcere que dele saíam para o restante da população.

Devido ao estado atual de nossas pesquisas, não estamos em condições de realizar um quadro mais vasto sobre a variedade das moléstias sofridas no cárcere, mas isso não impede certas generalizações referentes às principais doenças apresentadas, que periodicamente grassavam entre sua população. Soma-se a isso o fato de que também oferecemos alguns números relativos ao fluxo de presos pobres e particulares atendidos na enfermaria.

Com base na Tabela 2, a primeira observação que nos cabe diz respeito à preponderância dos presos pobres em comparação aos particulares. Isso, em realidade, só reforça os dados apresentados anteriormente sobre o perfil dos elementos humanos que povoavam a Casa de Correção e as cadeias da província sul-rio-grandense. ${ }^{15}$ 
Tabela 2: Presos pobres e particulares atendidos na enfermaria, 1856-1882

\begin{tabular}{|c|c|c|c|c|c|}
\hline \multirow[t]{2}{*}{ PERÍODO } & \multicolumn{2}{|c|}{ POBRES } & \multicolumn{2}{|c|}{ PARTICULARES } & \multirow[t]{2}{*}{ Total } \\
\hline & $\mathrm{H}$ & M & $\mathrm{H}$ & M & \\
\hline 1.1.1856-30.6.1856 & 77 & 1 & 5 & - & 83 \\
\hline 1.1.1857-30.6.1857 & 80 & 1 & 5 & - & 86 \\
\hline 1.7.1859-30.6.1860 & 45 & - & - & - & 45 \\
\hline 1.7.1860-30.6.1861 & 58 & 2 & 3 & - & 63 \\
\hline 1.7.1861-30.6.1862 & 36 & - & 3 & - & 39 \\
\hline 1.7.1862-31.12.1862 & 29 & - & - & - & 29 \\
\hline $1.1 .1863-31.12 .1863$ & 55 & - & 21 & - & 76 \\
\hline 1.1.1864-31.12.1864 & 26 & 1 & 3 & 1 & 31 \\
\hline 1.1.1865-31.12.1865 & 82 & - & 16 & - & 98 \\
\hline 1.1.1866-30.6.1866 & 51 & 1 & 6 & - & 58 \\
\hline 1.7.1866-30.6.1867 & 78 & 5 & 5 & 1 & 89 \\
\hline $30.11 .1868-30.11 .1869$ & 33 & - & 4 & - & 37 \\
\hline 1.12.1872-30.11.1873* & 3 & - & - & - & 3 \\
\hline 1.12.1873-30.6.1874 & 1 & - & - & - & 1 \\
\hline 1.7.1877-30.6.1878 & 10 & 1 & - & - & 11 \\
\hline 1.7.1879-30.6.1880 & 7 & - & - & - & 7 \\
\hline 1.7.1880-30.6.1881 & 3 & 1 & - & - & 4 \\
\hline 1.1.1882-30.11.1882 & 22 & 4 & - & - & 26 \\
\hline Total & 696 & 17 & 71 & 2 & 786 \\
\hline
\end{tabular}

Fontes: Coelho (1856); Camara (1857); Leão (1860, p.21-22, 1861, p.13-14); Rocha (1862, p.26-27); Pimentel (1863, p.29-30, 1864, p.34-36); Cunha (1866, p.32-34); Mello (1867, p.24-26); Sertorio (1870, p.16-17); Moraes (1874, p.19-20, 1875, p.27); Andrade (1879, p.77-78); D'Avila (1881, p.3233); Lima (1883, p.16-17).

* Os valores de 1872 até 1882 não dizem respeito ao total de atendidos, mas sim ao número de presos enfermos que "existiam" na enfermaria ao final do período indicado.

Como já dissemos, falta muito que perscrutar, mas fica novamente patente que a pobreza é a marca registrada desses estabelecimentos, visto que a maioria não podia pagar pelos serviços facultativos - o que é manifestado pela presença de 713 presos pobres em relação aos 73 particulares.

A tabela tem início no ano seguinte à ocupação da primeira seção da Casa de Correção e contempla diferentes períodos de atendimento na enfermaria para presos da Santa Casa de Misericórdia, até 1861 localizada nas dependências do mesmo hospital e posteriormente situada dentro do próprio estabelecimento penal.

Como se perceberá, nem todos os números são correspondentes ao total de enfermos tratados anualmente na respectiva enfermaria; em muitas ocasiões se apresentava apenas o fluxo semestral. Das anualidades disponíveis, a que mostrou o menor número de presos atendidos foi a de 1864, com apenas 31 enfermos. Coincidentemente, segundo o relatório da provedoria do HSCM de 1872 (Silva, 1872, p.7), também passaram naquele ano pela enfermaria só 31 reclusos; 64 em 1867 (Silva, 1867, p.10); e 63 indivíduos em 1868 (Silva, 1868, p.10).

Analisar o fluxo de entradas e saídas permite também observar em que medida o tratamento dado ali resultava positivamente para o restabelecimento do padecente. Conforme visto, os serviços prestados na enfermaria não se destacavam precisamente por sua qualidade e presteza. Servindo alimentos frios e medicamentos a destempo, sem enfermeiro próprio nem 
cozinheiro que a qualquer hora pudesse preparar uma alimentação prescrita pelo médico, chama realmente atenção o fato que, do total de 528 presos que deram baixa entre 1859 e 1867, 404 saíram "curados" (77\%), 75 faleceram (14\%) e 49 continuaram internados (9\%).

Gráfico 1: Estado dos presos atendidos na enfermaria entre $1^{\circ}$ de julho de 1859 e 30 de junho de 1867

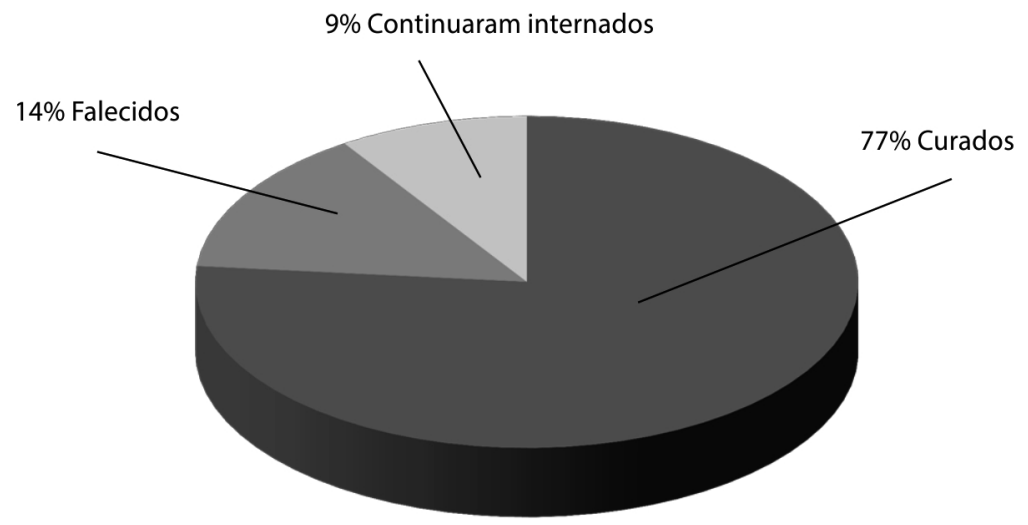

Fontes: Coelho (1856); Camara (1857); Leão (1860, p.21-22, 1861, p.13-14); Rocha

(1862, p.26-27); Pimentel (1863, p.29-30, 1864, p.34-36); Cunha (1866, p.32-34); Mello

(1867, p.24-26); Sertorio (1870, p.16-17).

Gráfico 2: Tempo de permanência na enfermaria, 1856-1862

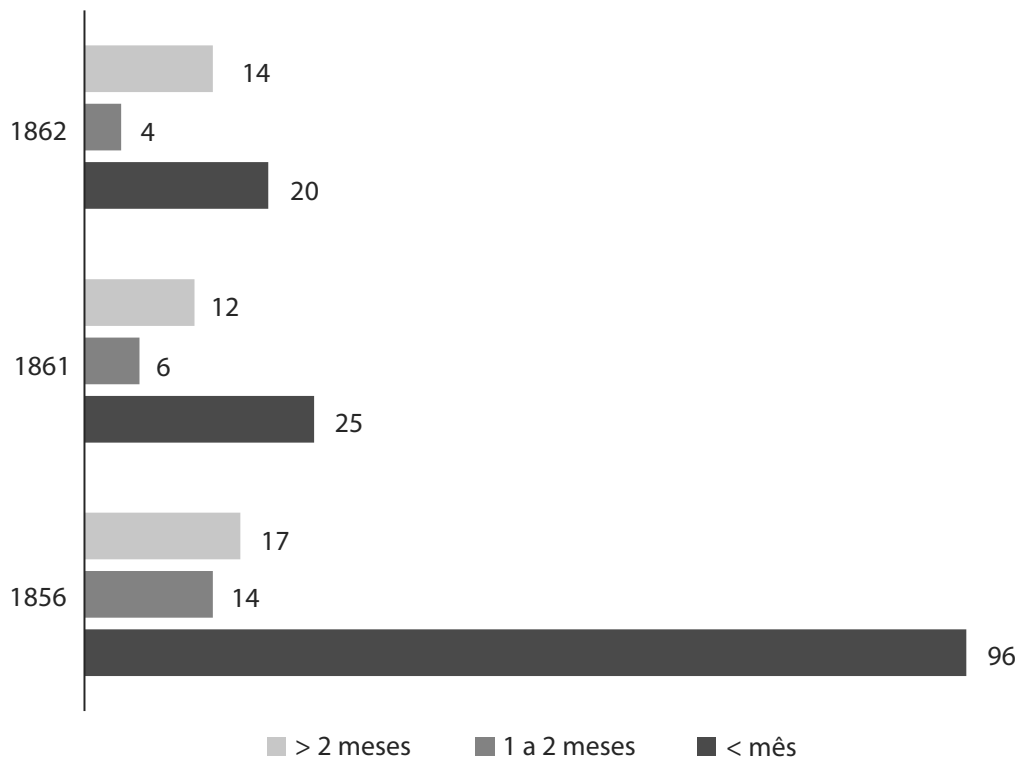

Fonte: Matrícula..., 1865.

Quanto ao tempo de permanência nos leitos da enfermaria, podemos inferir, com base na informação recolhida dos presos em 1856, 1861 e 1862, que o normal era a permanência de poucos dias, conforme demonstra o Gráfico 2. Pensamos que a alta rotatividade se devia em boa medida aos custos, precauções em face das fugas, mas também não se deve descartar outras hipóteses, como a possível limitação de leitos. 
Tudo indica que, ao mostrar sinais de melhora, o preso era reconduzido à sua cela, continuando apenas aqueles cujo quadro mais sério exigisse um cuidado intensivo. Nesse caso, como podemos ler no Gráfico 2, sua estada na enfermaria podia durar várias semanas e até meses. E os que não alongavam a estada nem retornavam aos cárceres, como já se sabe, dali saíam para o cemitério da cidade.

Para os três anos que compõem nossa amostra, verificamos 18 mortes de 208 presos (dez em 1856 e quatro para ambos os anos de 1861 e 1862), uma taxa de mortalidade de 8,65\%, resultando numa média de seis óbitos por ano. ${ }^{16}$ As doenças do sistema digestivo foram as mais fatais, contabilizando nove mortes: diarreia (cinco), gastrite crônica (uma), gastro-hepatite (duas) e constipação de ventre (uma). Em segundo lugar, com seis falecimentos, as afecções de ordem respiratória: tubérculos pulmonares (dois), pneumonia (dois), catarro pulmonar (um) e laringite (um). Houve, também, uma morte por bexigas confluentes, uma por oftalmia e outra por congestão cerebral.

\section{Considerações finais}

O tema desenvolvido neste artigo visou a duplo objetivo. Em primeiro lugar, analisar como a reforma penitenciária irrompeu com uma nova concepção punitiva que entranhava, desde os seus fundamentos, uma certa sensibilização acerca do tratamento do recluso. Essa sensibilização, porém, não foi fruto de um processo linear e harmônico, conforme demonstrado.

A criação e a ampliação de enfermarias no interior do estabelecimento penal, por exemplo, não significaram, por si só, melhoria substancial nas condições de vida da população reclusa. No entanto, não podemos negar que suas instalações, por mais modestas que fossem, constituíam um avanço no fluxo das sensibilidades penais, lembrando sempre que tais espaços eram inexistentes na maior parte do cenário carcerário brasileiro da segunda metade do século XIX. ${ }^{17}$

O segundo objetivo, que se entrelaça e complementa o primeiro, era ver como esse processo de sensibilização social dependia da absorção dos conceitos de "humanidade" e "civilização" por parte das classes governantes e letradas, as quais os reproduziam, formando ou consolidando uma opinião pública, como nesse caso, favorável ao aumento dos "mínimos vitais" dentro das instituições penais.

Isso, como já advertimos, não nega outros interesses menos nobres concernentes à disciplina, ao erário público, ou de prevenções com vistas ao bem-estar da população, pois, afinal de contas, para cuidar do próprio corpo, era indispensável o reconhecimento do "corpo" dos "demais": pobres, mendigos, escravos, enfermos, presos, loucos, crianças abandonadas etc. Sendo a criminalização e a exclusão social fenômenos que compartilham uma matriz "civilizadora" em comum, a mesma mão que se estende ao outro é a que reclui impiedosamente. 


\section{NOTAS}

${ }^{1}$ Nesta e nas demais citações de textos em outros idiomas, a tradução é livre.

${ }^{2}$ Ora, é evidente que cadeias existiam, o que faltava era um levantamento detalhado sobre a situação carcerária imperial. Essa desinformação também afetava muitos outros assuntos de primeira ordem, como o relativo à população, à saúde pública, à agricultura, à exploração mineral, ao comércio, às obras públicas, à administração pública etc. (Chalhoub, 2012, p.37).

${ }^{3}$ No original: “La represión del alma pareció al hombre 'civilizado' el camino ideal para ejercer 'influencias' por cuanto sus efectos eran más permanentes que los del castigo físico y a la vez ese método evitaba el horror ante el espectáculo del sufrimiento corporal, un tabú moderno".

${ }^{4}$ Ainda que esse "progresso" só possa ser entendido dentro de um marco de mudanças muito menos nobre, conforme ocorreu na reforma judiciária de 1871, aprovada oito dias antes da Lei do Ventre Livre. Segundo Koerner (1998, p.110), essa reforma visou assegurar a potestade dos senhores mediante instituições, que, como a polícia, tiveram sua autonomia reforçada por meio dos inquéritos e da manutenção das prisões preventivas ante os "riscos" de um "processo de transição gradual para o trabalho livre".

${ }^{5}$ Por motivos normativos que limitam este trabalho, para situar melhor o papel do Hospital da Santa Casa de Misericórdia de Porto Alegre entre os espaços e as práticas de cura no Rio Grande do Sul, ainda que seu recorte seja para o período imediato posterior ao nosso, reportamo-nos a Weber (1999).

${ }^{6}$ Deve-se registrar que tanto o ingresso na enfermaria como o traslado para o hospital eram práticas frequentemente utilizadas como trampolim para possíveis planos de evasão. A historiografia sobre a história das prisões há muito vem expressando a recorrência do uso desses espaços físicos e sociais nas manobras estratégicas de fuga e sobrevivência no cárcere. Dores e indisposições simuladas, assim como outros fingimentos, não deviam ser incomuns quando interessava o internamento. É, nesse sentido, ao menos sugestiva a expressão "nenhuma" escrita na coluna das "moléstias" do preso Raimundo da Silveira Gularte, filho de Manoel da Silveira, solteiro, 50 anos, dessa província e sem profissão, com entrada na enfermaria da Santa Casa no dia 27 e tendo recebido alta no dia 29 de fevereiro de 1856 (Matrícula..., 1865). Para algumas belas e entretidas páginas sobre o microcosmo carcerário na Casa de Correção de Porto Alegre, ver "Recordações da casa dos mortos: a Casa de Correção" (Moreira, 2009, p.118-152) e "Burlando o controle e a disciplina: manobra dos encarcerados" (Szczepaniak, 2006, p.89-94).

${ }^{7}$ Essas mesmas queixas foram repetidas quase textualmente três anos depois, por Henrique Pereira de Lucena (1887, p.124). Uma comissão nomeada pela Câmara Municipal para visitar a Casa de Correção, o Hospício São Pedro e a Santa Casa de Misericórdiba, em 1885, também fez menção à ineficácia dos serviços prestados (Pesavento, 2009, p.40).

${ }^{8}$ Existe uma rica bibliografia especializada sobre a história social da saúde e da doença, além das diferentes "artes de curar", como, por exemplo: Le Goff (1990); Nascimento, Carvalho (2004); Sampaio (2002); Chalhoub (2003); Pimenta (1998); Figueiredo (1999); Witter (2000); e, para uma resenha sobre a última, ver Engel (2004).

${ }^{9}$ Como será visto, mais de 50\% da amostra composta pelos enfermos nos anos de 1856, 1861 e 1862 nasceu fora do Rio Grande do Sul. E, certamente, entre os "naturais", deviam apresentar origem elevadamente diversificada, já que a Casa de Correção recebia presos oriundos das mais distantes comarcas da província. Não obstante, entendemos pertinente informar que o censo de 1872 computava para Porto Alegre 44.007 habitantes, incluídos os escravos, que, mesmo apresentando número subestimado, alcançavam 8.155 pessoas. Da população livre (35.852), 18.365 eram homens, e 17.487 mulheres; 25.326 solteiros, 8.187 casados, e 2.339 viúvos; e se dividimos o total entre brasileiros e estrangeiros, temos 38.632 e 5.375, respectivamente. Esses dados são adaptados de Monastério (s.d.).

${ }^{10} \mathrm{Um}$ bom exemplo do que estamos tratando é o estudo sobre a vida dos escravos no Rio de Janeiro realizado por Karasch (2000). Para um contexto mais amplo, ver Eugênio (2010) e Abreu (2005).

${ }^{11}$ Para o total de 268 presos ingressados no hospital de Salvador em 1865, segundo Trindade (2011, p.1078), 14,9\% deram entrada com problemas do sistema respiratório (40); 13,1\% devido a afecções do sistema digestivo (35), e se não fosse pelas "variadas", que alcançaram a porcentagem de 9,3\% (25), teríamos a mesma sequência tipológica de doenças verificada em nosso caso, visto que as infectoparasíticas entrariam em terceiro lugar com 7,8\% (21). Para outras cartografias penais, também há estudos que corroboram essa tendência de maior incidência entre as doenças englobadas nas categorias aqui trabalhadas (gastrintestinais, respiratórias e infectoparasíticas) sobre as demais dolências desenvolvidas pela população reclusa ou com ela levadas às prisões. Sobre Portugal, ver Santos (1999, p.286-287); para diferentes realidades e instituições penitenciárias da geografia espanhola no século XIX, ver Gómez Bravo (2005, p.201-202), Oliver Olmo (2001, p.297-299), Cesar (2010, p.290-302); para o caso da França durante o mesmo período, ver Petit (1990, p.528-532). 
${ }^{12}$ Segundo Witter (2007, p.83, 80): "No dia 30 de abril do ano de 1856, a Comissão de Higiene Pública declarou extinta a epidemia na província do Rio Grande do Sul. O governo preocupou-se em oferecer ajuda a viúvas e órfãos da epidemia, contando inclusive com doações do próprio imperador, que, recém-casado, visitou a província em junho daquele ano. Para esse caso foi instituída uma comissão de notáveis que se encarregou de fazer a distribuição dos donativos". Oficialmente, a infestação de cólera-morbo só fora confirmada por volta de 26 de novembro do ano anterior, pelo então presidente da província, barão de Muritiba.

${ }^{13}$ Lembramos, igualmente, que, devido ao crescente rechaço ante as cenas de sofrimento alheio, geradas pela sensibilidade civilizada, tornou-se comum e institucionalizada a prática de castigar cativos no interior das cadeias. Para a capital da província, Moreira (2009, p.119) localizou a introdução desse procedimento no Código de Posturas, em 10 de fevereiro de 1831, e tudo indica que essa foi a tendência também em outras povoações da província. Tramontini (2000, p.16), por exemplo, documentou para a colônia de São Leopoldo, por meio das atas da câmara de 5 de julho de 1848, uma proposta de colocar um palanque no interior da cadeia para executar castigos, visto que, moralmente, não era bem-visto fazê-lo publicamente na rua.

${ }^{14}$ Havia, em fevereiro de 1878, 41 "infelizes que perderam a razão" na Santa Casa de Misericórdia e outros 21 (14 homens e sete mulheres), na Casa de Correção (Lemos, 1878, p.67). No final do mesmo ano, solicitou-se à repartição de Obras Públicas um projeto de "compartimentos para loucos", a ser construídos "no galpão junto ao corpo da guarda" (Silva, 1879, p.14). Sobre a Casa de Misericórdia de Pelotas, ver Tomaschewski (2007).

${ }^{15}$ Para uma visão panorâmica sobre o estado da rede carcerária sulina na segunda metade do XIX, ver Cesar (2012, p.1112-1127).

${ }^{16}$ Se computarmos os anualmente falecidos comunicados pela provedoria da Santa Casa para 1867 (11), 1868 (13) e 1872 (seis), essa média atinge 9,66 presos.

${ }^{17}$ Tudo indica que, até bem depois de inaugurados, muitos dos correcionais do Império, bem como as prisõesmodelo, não dispunham de locais apropriados para enfermaria. Para o Rio Grande do Sul, onde havia Casas de Misericórdia, eram enviados os enfermos, como Pelotas, Rio Grande, São Gabriel etc. A Casa de Prisão com Trabalho de Salvador (Bahia), por exemplo, não contava, todavia, em 1865, com uma enfermaria própria, segundo Trindade (2011, p.1074).

\section{REFERÊNCIAS}

ABREU, Jean L.N.

Das enfermidades e dos saberes sobre o corpo dos africanos no Brasil: historiografia, práticas e apropriações. História e Perspectivas, v.1, n.32-33, p.179-194. 2005.

AGUIRRE, Carlos.

Cárcere e sociedade na América Latina, 18001940. In: Maia, Clarisa N. et al. (Org.). História das prisões no Brasil. v.1. Rio de Janeiro: Rocco. p.35-77. 2009.

ANDRADE, Americo M.M. de.

Relatório com que o exm. sr. dr. Americo de Moura Marcondes de Andrade passou a administração desta província ao exm. sr. dr. Felisberto Pereira da Silva no dia 26 de janeiro de 1879. Porto Alegre: Tipographia do Jornal do Comércio. 1879.

AZEVEDO, Manoel A.D. de.

Relatório apresentado à Assembleia Geral Legislativa na segunda sessão da $15^{a}$ legislatura pelo respectivo ministro e secretario de Estado dos Negócios da Justiça dr. Manoel Antonio Duarte de Azevedo. Rio de Janeiro: Tipografia Americana. 1873.

BARRÁN, José P.

Historia de la sensibilidad en el Uruguay: el disciplinamiento (1860-1920). t.2. Montevideo:
Ediciones de la Banda Oriental/Facultad de Humanidades y Ciencias. 1991.

CAMARA, Patricio C. da.

Relatório do vice-presidente da Província de S. Pedro do Rio Grande do Sul, o comendador Patricio Correa da Camara, na abertura da Assembleia Legislativa Provincial em 11 de outubro de 1857. Porto Alegre: Tipographia do Mercantil. 1857.

CESAR, Tiago $S$.

A ilusão panóptica: encarcerar e punir nas imperiais cadeias da província de São Pedro. In: Encontro Estadual de História, 11., Anais eletrônicos... Rio Grande: Universidade Federal do Rio Grande. p.1112-1127. Disponível em: http://www.eeh2012.anpuh-rs.org.br/ resources/anais/18/1346375515_ARQUIVO_ AilusaopanopticaANPUH.pdf. Acesso em: 19 maio 2015. 2012.

CESAR, Tiago $S$.

La cárcel y el control del delito en Córdoba durante el cambio de siglo (1875-1915). Córdoba: Servicio de Publicaciones de la Universidad de Córdoba. 2010. 
CHALHOUB, Sidney.

População e sociedade. In: Carvalho, José M. (Coord.). A construção nacional, 1830-1889. v.2. Rio de Janeiro: Objetiva. p.37-81. 2012.

CHALHOUB, Sidney (Org.).

Artes e ofícios de curar no Brasil: capítulos de história social. Campinas: Editora da Unicamp. 2003.

COELHO, Jeronymo F.

Relatório do presidente da Província de S. Pedro do Rio Grande do Sul, Jeronymo Francisco Coelho, na abertura da Assembleia Legislatura Provincial em 15 de dezembro de 1856. Porto Alegre: Tipografia do Mercantil. 1856.

COELHO JUNIOR, Antonio.

Relatório que a Presidência da província dirigiu o provedor da Santa Casa de Misericórdia José Antonio Coelho Junior em 7 de fevereiro de 1873. Porto Alegre: Tipografia do Comércio. 1873.

CUNHA, Antonio A.P. da.

Relatório apresentado pelo presidente da Província Antonio Augusto Pereira da Cunha ao seu sucessor no dia 31 de outubro de 1866. Porto Alegre: Tipografia do Jornal do Comércio. 1866.

D'AVILA, Henrique.

Relatório com que o exm. sr. dr. Henrique D'avila entregou a administração da província do Rio Grande do Sul, em 4 de março de 1881. Porto Alegre: Tipografia A Reforma. 1881.

DUPRAT, Catherine.

Punir et guérir: en 1819, la prison des philanthropes. In: Perrot, Michelle. L'impossible prison: recherches sur le système pénitentiaire au XIXe siècle. Paris: Seuil. p.64-122. 1980.

ENGEL, Magali G.

Por uma história das práticas de cura. História, Ciência, Saúde - Manguinhos, v.11, n.2, p.431-433. 2004.

EUGÊNIO, Alisson.

Reflexões médicas sobre as condições de saúde da população escrava no Brasil do século XIX. AfroÁsia, v.2, n.42, p.125-156. 2010.

FAGUNDES, João R.F.

Relatório da Santa Casa da Misericórdia da cidade de Porto Alegre, capital da província de S. Pedro do Rio Grande do Sul no ano de 1855, acompanhado do balanço da receita e despesa da mesma, apresentado na entrega da administração pelo provedor dr. João Rodrigues Fagundes. Rio de Janeiro: Tipografia Episcopal de Agostinho de Freitas Guimarães \& Cia. 1856.

FEIJÓ, Diogo A.

Relatorio do ex.mo ministro da Justiça do ano de 1831 apresentado à Assembleia Geral Legislativa na sessão ordinaria de 1832. Rio de Janeiro:
Tipografia Imperial e Constitucional de E. Seignot-Plancher. 1832.

FIGUEIREDO, Betânia.

Barbeiros e cirurgiões: atuação dos práticos ao longo do século XIX. História, Ciência, Saúde Manguinhos, v.6, n.2, p.277-291. 1999.

FOUCAULT, Michel.

Vigiar e punir: nascimento da prisão. Petrópolis: Vozes. 2012.

FRANÇA, Clemente F.

Conta, que a sua majestade o imperador dá o ministro e secretário de Estado dos Negócios da Justiça, do tempo da sua administração. Rio de Janeiro: Tipographia Imperial e Nacional. 1826.

GÓMEZ BRAVO, Gutmaro.

Crimen y castigo: cárceles, justicia y violencia en la España del siglo XIX. Madrid: Catarata. 2005.

KARASCH, Mary C.

A vida dos escravos no Rio de Janeiro (1808-1850). São Paulo: Companhia das Letras. 2000.

KOERNER, Andrei.

O poder judicial na ordem política imperial. São Paulo: Hucitec. 1998.

LEÃO, Joaquim A.F.

Relatório com que o conselheiro Joaquim Antão Fernandes Leão entregou a Presidência da Província de S. Pedro do Rio Grande do Sul ao exm. sr. vicepresidente comendador Patricio Correa da Camara. Porto Alegre: Tipografia do jornal A Ordem. 1861.

LEÃO, Joaquim A.F.

Relatório apresentado à Assembleia Provincial de $S$. Pedro do Rio Grande do Sul, na primeira sessão da nona legislatura pelo Conselheiro Joaquim Antão Fernandes Leão. Porto Alegre: Tipografia do Correio do Sul. 1860 .

LEÃO, Joaquim A.F.

Relatorio apresentado a Assembléa Provincial de $S$. Pedro do Rio Grande do Sul na segunda sessão da oitava legislatura pelo conselheiro Joaquim Antão Fernandes Leão. Porto Alegre: Tipografia do Correio do Sul. 1859.

LE GOFF, Jacques.

As doenças têm história. Lisboa: Terramar. 1990.

LEMOS, Francisco F.

Relatorio com que o exm. sr. desembargador

Francisco de Faria Lemos passou a administração desta província ao exm. sr. dr. João Chaves Campello, segundo vice-presidente, no dia 10 de fevereiro de 1878. Porto Alegre: Tipografia do Jornal do Comércio. 1878.

LIMA, José A.S.

Fala dirigida à Assembleia Legislativa pelo presidente conselheiro José Antonio de Souza Lima, na $1^{a}$ Sessão 
da $21^{a}$ Legislatura. Porto Alegre: Tipografia do Jornal do Comércio. 1883.

LUCENA, Henrique P. de.

Fala apresentada à Assembleia Legislativa Provincial do Rio Grande do Sul pelo presidente da província o exm. sr. desembargador Henrique Pereira de Lucena ao instalar-se a segunda Sessão da $21^{a}$ legislatura em 7 de março de 1886. Porto Alegre: Oficinas Tipográficas do Conservador. 1887.

MATRÍCULA...

Matrícula geral dos enfermos 1856-1865. Livro

2. (Centro de Documentação e Pesquisa da Santa Casa de Misericórdia). Porto Alegre. 1865.

MCGOWEN, Randall.

The Well-Ordered Prison: England, 1780-1865. In: Morris, Norval; Rothman, David J. (Org.). The Oxford history of the Prison: the practice of punishment in western society. New York/ Oxford: Oxford University Press. p.71-99. 1998.

MELLO, Francisco I.M.H. de.

Fala dirigida à Assembleia Legislativa da Província de S. Pedro do Rio Grande do Sul pelo presidente dr. Francisco Ignacio Marcondes Homem de Mello, na segunda sessão da $12^{a}$ Legislatura. Porto Alegre: Tipografia do Rio-Grandense. 1867.

MONASTÉRIO, Leonardo.

Censo de 1872. Coden/UFPel. Diponível em: ich. ufpel.edu.br/economia. Acesso em: 15 jan. 2012. s.d.

MORAES, João P.C. de.

Fala dirigida à Assembleia Legislativa da província de S. Pedro do Rio Grande do Sul pelo presidente dr. João Pedro Carvalho de Moraes em primeira sessão da $16^{a}$ Legislatura. Porto Alegre: Tipografia do Rio-Grandense. 1875.

MORAES, João P.C. de.

Relatório da presidência da Província de S. Pedro do Rio Grande do Sul, o dr. João Pedro Carvalho de Moraes, em 7 de março de 1874. Porto Alegre: Tipografia do Rio-Grandense. 1874.

MOREIRA, Paulo R.S.

Entre o deboche e a rapina: os cenários sociais da criminalidade popular em Porto Alegre. Porto Alegre: Armazém Digital. 2009.

MURITIBA, Barão de.

Relatório com que o conselheiro Barão de Muritiba entregou a presidência da Província de S. Pedro do Rio Grande do Sul ao exm. sr. presidente e comandante das Armas, conselheiro e general Jeronymo Francisco Coelho no dia 28 de abril de 1856. Porto Alegre: Tipografia do Mercantil. 1856.
NASCIMENTO, Dilene R.; CARVALHO, Diana M. de (Org.).

Uma história brasileira das doenças. Brasília:

Paralelo 15. 2004.

OLIVER OLMO, Pedro.

Cárcel y Sociedad Represora: la criminalización del desorden en Navarra (siglos XVI-XIX). Bilbao: Universidad del País Vasco. 2001.

PERROT, Michelle.

Os excluídos da história: operários, mulheres e prisioneiros. São Paulo: Paz e Terra. 2006.

PESAVENTO, Sandra J.

Visões do cárcere. Porto Alegre: Zouk. 2009.

PETIT, Jacques-Guy.

Ces peines obscures: la prison pénale en France 1780-1875. Ligugê: Fayard. 1990.

PIMENTA, Tânia S.

Barbeiros, sangradores e curandeiros no Brasil (1808-28). História, Ciência, Saúde - Manguinhos, v.5, n.2, p.349-374. 1998.

PIMENTEL, Espiridião E.B.

Relatório apresentado pelo presidente da Província de S. Pedro do Rio Grande do Sul, dr. Espiridião Eloy de Barros Pimentel, na primeira Sessão da $11^{a}$ Legislatura da Assembleia Provincial. Porto Alegre: Tipografia do Correio do Sul. 1864.

PIMENTEL, Espiridião E.B.

Relatório apresentado pelo presidente da Província de S. Pedro do Rio Grande do Sul, dr. Espiridião Eloy de Barros Pimentel, na segunda Sessão da décima Legislatura da Assembleia Provincial. Porto Alegre: Tipografia do Correio do Sul. 1863.

PRATT, John.

Castigo y civilización: una lectura crítica sobre las prisiones y los regímenes carcelarios. Barcelona: Gedisa. 2006.

REGULAMENTO...

Regulamento especial da cadeia civil de Porto Alegre, 27 fev. 1857. In: Seminário de Pesquisas do AHRS, 1., 2001, Porto Alegre. Anais... Porto Alegre: Arquivo Histórico do Rio Grande do Sul. 2001.

REQUERIMENTO...

Requerimento do preso Germano TH Wagner, 19 dez. 1885. In: Seminário de Pesquisas do AHRS, 1., 2001, Porto Alegre. Anais... Porto Alegre: Arquivo Histórico do Rio Grande do Sul. 2001.

ROCHA, Francisco A.P.

Relatório apresentado pelo presidente da Província de S. Pedro do Sul, desembargador Francisco de Assis Pereira Rocha, na primeira Sessão da décima Legislatura da Assembleia Provincial. Porto Alegre: Tipografia do jornal A Ordem. 1862. 
ROTHMAN, David J.

Perfecting the prison: United States, 1789-1865. In: Morris, Norval; Rothman, David J. (Org.). The Oxford history of the prison: the practice of punishment in western society. New York/ Oxford: Oxford University Press. p.100-116. 1998.

SAMPAIO, Gabriela R.

Nas trincheiras da cura: as diferentes medicinas no Rio de Janeiro Imperial. Campinas: Unicamp/ Cecult. 2002.

SANTOS, Maria J.M.

A sombra e a luz: as prisões do liberalismo. Porto: Edições Afrontamento. 1999.

SERTORIO, João.

Relatório com que o excelentíssimo sr. dr. João Sertorio, presidente desta Província, passou a administração da mesma ao exm ${ }^{o}$. sr. dr. João Capistrano de Miranda e Castro, primeiro vicepresidente, no dia 29 de agosto de 1870 . Porto Alegre: Tipografia do Rio-Grandense. 1870.

SILVA, Felisberto P.

Fala dirigida à Assembleia Legislativa da província de S. Pedro do Rio Grande do Sul pelo presidente dr. Felisberto Pereira da Silva na $1^{a}$ Sessão da $18^{a}$ Legislatura. Porto Alegre: Tipografia do Jornal do Comércio. 1879.

SILVA, Luiz M.L.

Relatorio do Estado da Santa Casa de Misericordia da cidade de Porto Alegre, capital da província de $S$. Pedro do Sul, acompanhado do balanço da receita e despesa apresentado pelo provedor marechal de campo Luiz Manoel de Lima e Silva, no ano compromissal de 1872. Porto Alegre: Tipografia do Constitucional. 1872.

SILVA, Luiz M.L.

Relatório do Estado da Santa Casa de Misericórdia da cidade de Porto Alegre, capital da província de $S$. Pedro do Sul, acompanhado do balanço da receita e despesa, apresentado pelo provedor marechal de campo Luiz Manoel de Lima e Silva, no ano compromissal de 1868. Porto Alegre: Tipografia de Jose Antonio Lessa. 1868.

SILVA, Luiz M.L.

Relatório do estado da Santa Casa de Misericórdia da cidade de Porto Alegre, capital da província de S.
Pedro do Sul, acompanhado do balanço da receita e despesa, apresentado pelo provedor marechal de campo Luiz Manoel de Lima e Silva, no ano compromissal de 1867. Porto Alegre: Tipografia do Jornal do Comércio. 1867.

SILVA, Mozart L.

Eugenia, antropologia criminal e prisões no Rio Grande do Sul. Santa Cruz do Sul: Edunisc. 2005.

SZCZEPANIAK, Ivone.

A busca pelo cárcere perfeito: Casa de Correção de Porto Alegre, 1835-1913. Dissertação (Mestrado em Integração Latino-Americana) - Universidade Federal de Santa Maria, Santa Maria. 2006.

TOMASCHEWSKI, Cláudia.

Caridade e filantropia na distribuição da assistência: a Irmandade da Santa Casa de Misericórdia de Pelotas - RS (1847-1922). Dissertação (Mestrado em História) - Pontifícia Universidade Católica do Rio Grande do Sul, Porto Alegre. 2007.

TRAMONTINI, Marcos J.

A escravidão na colônia alemã - São Leopoldo, primeira metade do século XIX. In: Primeiras Jornadas de História Regional Comparada - Rio Grande do Sul, Uruguay, Corrientes, Santa Fé, Entre Rios, Córdoba e Missiones, 2000, Porto Alegre. Anais... Porto Alegre: Ipea; PUC; FEE. p.1-17. 2000.

TRINDADE, Cláudia M.

Doenças, alimentação e resistência na penitenciária da Bahia, 1861-1865. História, Ciência, Saúde - Manguinhos, v.18, n.4, p.10731093. 2011.

WEBER, Beatriz T.

As artes de curar: medicina, religião, magia e positivismo na República Rio-grandense - 18891928. Santa Maria: UFSM; Bauru: Edusc. 1999.

WITTER, Nikelen A.

Males e epidemias: sofredores, governantes e curadores no sul do Brasil (Rio Grande do Sul, século XIX). Tese (Doutorado em História) Universidade Federal Fluminense, Niterói. 2007.

WITTER, Nikelen A.

Dizem que foi feitiço: as práticas de cura no Sul do Brasil (1840-1880). Porto Alegre: EDIPUCRS. 2000. 